\title{
A rare case report of hysterotomy for retained placenta accreta in bicornuate uterus
}

\author{
Reena Sharma $^{1}$, Amit Gupta ${ }^{1}$, Usha K. Chaudhary ${ }^{2}$, Ajay Sharma ${ }^{3}$, Arvind Kumar ${ }^{4}$
}

\begin{abstract}
${ }^{1}$ Department of Gynaecology \& Obstetrics, ${ }^{2}$ Department of Anaesthesia, ${ }^{3}$ Department of Cardiology, ${ }^{4}$ Department of Pharmacology, Dr. RPGMC Tanda, Kangra, Himachal Pradesh, India
\end{abstract}

Received: 28 July 2015

Revised: 17 August 2015

Accepted: 19 August 2015

\section{*Correspondence:}

Dr. Reena Sharma,

E-mail: dreenajay@gmail.com

Copyright: $\odot$ the author(s), publisher and licensee Medip Academy. This is an open-access article distributed under the terms of the Creative Commons Attribution Non-Commercial License, which permits unrestricted non-commercial use, distribution, and reproduction in any medium, provided the original work is properly cited.

\begin{abstract}
Retained placenta is a common third stage complication. Placenta accreta is due to abnormal invasive placental implantation. Many cases of Post-partum haemorrhage (PPH) are caused by placenta accreta and may lead to peripartum hysterectomy. We here report a case of placenta accreta in a patient following two failed attempts of manual removal of retained placenta followed by conservative management with methotrexate in stable patient. Both attempts were unsuccessful and led to septicaemia, requiring delivery of placenta by hysterotomy.
\end{abstract}

Keywords: Retained placenta, Placenta accreta, Methotrexate

\section{INTRODUCTION}

Placenta accreta is general term when part or the entire placenta invades and is inseparable from the uterine wall. ${ }^{1}$ It is caused by defective decidua basalis resulting in abnormal invasive placental implantation, associated with significant maternal mortality and morbidity. ${ }^{2}$ The invasion of superficial myometrium is placenta accreta, invasion into deeper myometrial layer is placenta increta, and invasion through the serosa and/ or adjacent pelvic organs is placenta percreta. ${ }^{3}$ Most of the cases are diagnosed at the time of delivery when failed attempts during manual removal of placenta. ${ }^{4}$ It may result in massive obstetric haemorrhage, leading to disseminated intravascular coagulopathy, may need hysterectomy, surgical injury to ureter, bladder, bowel or neurovascular structures, adult respiratory distress syndrome, acute transfusion reaction, electrolyte imbalance, renal failure, infectious morbidities and loss of fertility. ${ }^{2,5}$ Maternal mortality is high up to $9 \% .{ }^{6}$ Ultrasonography is sufficient to diagnose placenta accreta with a sensitivity of $77-87 \%$ and $96-98 \%$ specificity. ${ }^{7,8}$ Methotrexate has been proposed as an adjunctive treatment for placenta accreta. ${ }^{9,10}$ But there is no consensus whether this therapy is any more effective than observation. ${ }^{11}$ The safest and most common treatment is a planned caesarean hysterectomy if placenta accreta is diagnosed before birth. ${ }^{2,12}$ Here we are presenting a case of 23 years primipara with retained placenta accreta with bicrnuate uterus.

\section{CASE REPORT}

A 23 years old primiparous woman reported in emergency labour room on21/9/14 at $6.00 \mathrm{pm}$ referred from some peripheral health centre with history of vaginal delivery with episiotomy at term 8 hours back on same day with retained placenta. At the time of admission patient was conscious, comfortable, pulse rate 96/min, BP $110 / 60 \mathrm{mmHg}$, afebrile, pallor present and her haemoglobin was $8 \mathrm{gm} \%$, per abdomen - Uterus 26-28 week size, well retracted, per speculum- episiotomy not stitched, no bleeding, no cord seen. Per vaginum exam.os closed, placental margin/ cord not felt, no bleeding. Patient was taken to operation theatre for manual removal of placenta (MROP) under general anaesthesia on same 
day. The surgeon was only able to remove small bits of placental tissue; rest of the placenta was densely adherent to the myometrium. Intraoperative bleeding was managed with uterine massage, uterotonic drugs and vaginal packing and decision of conservative management was taken to save the future fertility of patient as she was primiparous. Strict monitoring of vitals, vaginal bleeding and temperature charting done. Intravenous antibiotics started. Vaginal packing removed after 24 hours of MROP. There was no active bleeding. Post MROP ultrasound done- showing heterogeneous hypoechoic area of approx. $10.1 \times 6.8 \mathrm{~cm}$ in uterine cavity of left horn [Figure 1].

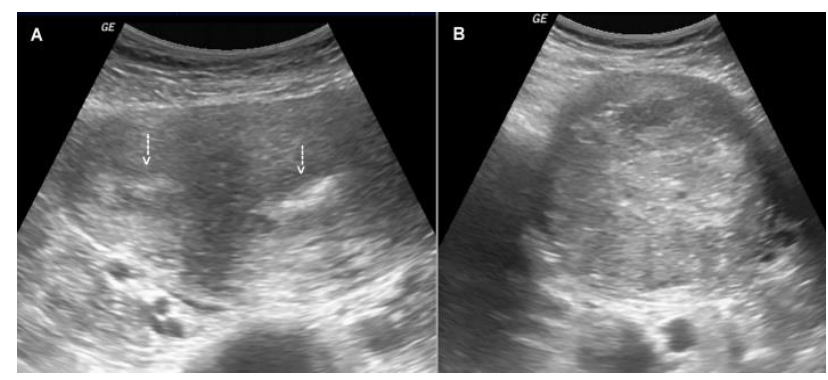

Figure 1: Ultrasound showing heterogenous hypoechoic area of approximately $10.1 \times 6.8 \mathrm{~cm}$ in left horn of uterine cavity suggestive of retained placenta, uterus appears bicornuate with empty right cornua.

Uterus appears bicornuate with empty right cornua. Magnetic resonance imaging (MRI) advised for further evaluation. Her haemoglobin was $6 \mathrm{gm} \%$ so two units of $\mathrm{AB}$ positive blood transfusions were given. On MRI, there was bicornuate uterus with post partal changes in left uterine horn with retained placenta and focal thinning with indistinctness of the inner myometrial thinning at places( posterior aspect)- possibility of placenta accrete [Figure 2].

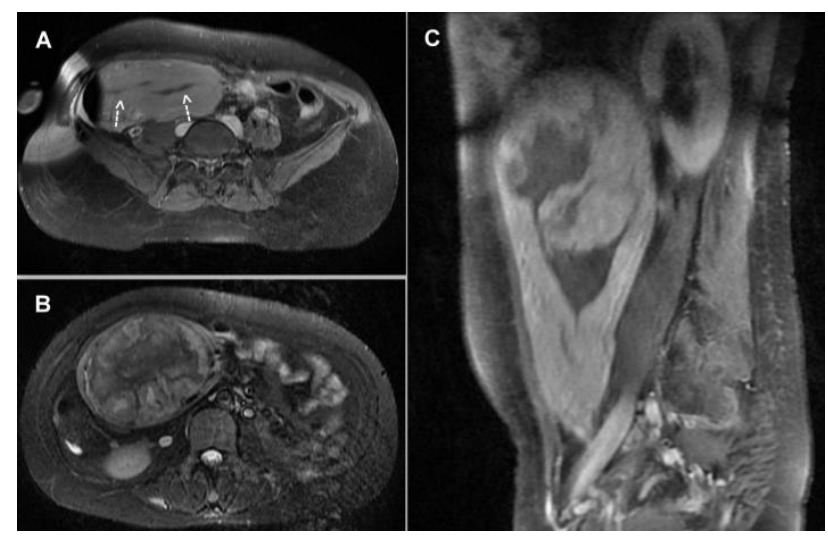

Figure 2: Axial post gadolinium fat saturated T1 weighted MRI image (A) showing two separate cavities in the body of uterus .axial fat saturated T2 image (B) and sagittal fat saturated gadolinium T1 image $(C)$ showing retained placenta within the left horn of uterus.
After MRI report, informed consent of hysterectomy was taken and MROP again attempted on $7^{\text {th }}$ PND after arranging 4 units of blood. Intraoperatively- uterus 28week size, appear bicornuate, right horn is empty, left horn having retained placenta. Small fragments of placenta (approximately $4.0 \times 5.0 \mathrm{~cm}$ size) removed with difficulty as placenta was densely adherent. There was no postpartum haemorrhage. As patient was primiparous and relatives of the patient had given consent that hysterectomy should be the last resort after exhausting all conservative measures, so on table decision was taken to start the conservative management with methotrexate to conserve the future fertility of the patient. Patient was put on Intravenous antibiotics, piperacillin+Tazobactum and metronidazole under strict monitoring with watch for vitals, vaginal bleeding and temperature charting. Review ultrasonography showed retained placenta of size $8.1 \times 7.1 \mathrm{~cm}$ with thinning of myometrium overlying [Figure 3].
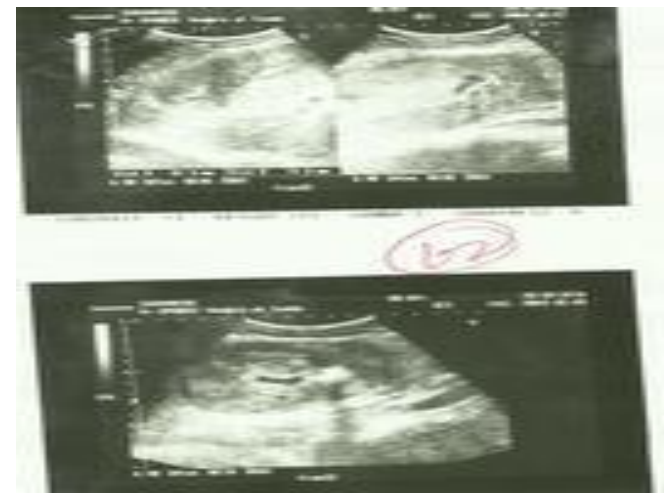

Figure 3: Follow up ultrasonography after MROP showing retained placenta of size $8.1 \times 7.1 \mathrm{~cm}$ with thinning of myometrium overlying.
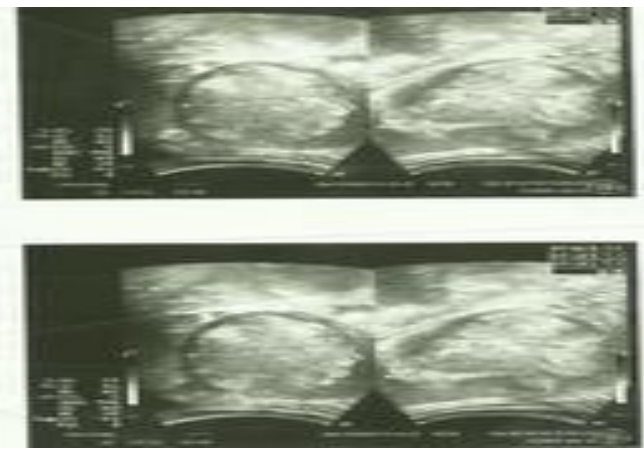

Figure 4: Follow up ultrasonography after Injection Methotrexate showing retained placenta of size $7.9 \times 3.8 \times 5.7 \mathrm{~cm}$.

Injection Methotrexate 50mg intramuscular given on 9th PND. Patient started having fever $101 \circ \mathrm{F}$ on 13 th PND (6th post MROP day). Her Haemoglobin was $7.6 \mathrm{gm} \%$, TLC 6800cmm, DLC N 67-L 23-E3-M7. Fever may also represent an inflammatory response to tissue necrosis after giving methotrexate in the absence of any infectious source, and lab parameters were not suggestive of sepsis. 
Injection Methotrexate repeated after 1 week. Follow up ultrasonography was showing retained placenta of size $7.9 \times 3.8 \times 5.7 \mathrm{~cm}$ [Figure 4].

Two more blood transfusions given. Patient was having fever $101^{\circ}$ F daily. Widal serology, Weil Felix serology, endocervical swab, urine \& blood culture sensitivity were within normal limits. TLC $3800 \mathrm{cmm}$, DLC N50- L38 E4- M8, ESR 54, platelet count $265000 / \mathrm{mm}^{3}$, Renal function tests and Liver function tests were within normal limits, Haemoglobin 6.3 gm\%. Repeat TLC $2100 \mathrm{cmm}$, DLC N47-E3-L44-M6 on the same day. There was no history of distension abdomen, nausea- vomiting, abdominal pain, vaginal bleeding. Urinary and bowel habits were normal, but there was decreased oral intake and continuous fever with peak of $103^{\circ} \mathrm{F}$. Two more blood transfusions given. As lab parameters started deteriorating, on the same day lab parameters repeated, physician consulted who kept the possibility of sepsis, blood arranged and immediately emergency exploratory laparotomy planned on the same day $\left(27^{\text {th }}\right.$ ostpartum day). Informed consent for possible complications and exploratory laparotomy precede hysterectomy was taken although husband again impressed that hysterectomy should be the last resort after exhausting other options. Intraoperatively- left cornual region of the uterus was dilated and occupied by placenta. Single cavity of uterus, no septum felt within cavity. Left tube oedematous and inflamed with purulent discharge coming through the fimbrial side of the same tube, omentum adherent over the body of uterus on left side. A decision to attempt a hysterotomy prior to hysterectomy was made on table. After reflecting uterovesical fold $3-4 \mathrm{~cm}$ Low transverse uterine incision given and with the help of sponge holding forceps whole of the placenta removed piecemeal but completely from the fundus of left side of uterus. Uterus stitched in 2 layers. Post-operatively patient was given IV piperacillin+Tazobactum and metronidazole and fluids under strict monitoring. On 1st POD patient was afebrile, Haemoglobin 8.0gm\%, TLC 10500/cmm, DLC N67- L 23-E 7-M 3, platelets 2.7lakhs / $\mathrm{mm}^{3}$, passing flatus, orally allowed, put on oral antibiotics oflxacin and ornidazole. Stitches removed on 8th POD. Patient was discharged on 11th POD (38th PPD) with appropriate counselling for the need of a caesarean delivery in next pregnancy. Patients called for follow up with HPE report of tissue sent and advised repeat MRI/HSG after 6weeks to rule out bicornuate uterus.

\section{DISCUSSION}

The incidence of placenta accreta has increased over the past century from $1 / 7000$ deliveries to $1 / 2500$ deliveries due to increased rates of caesarean deliveries. ${ }^{13}$ The importance of antenatal diagnosis of placenta accreta in high risk pregnancies is to permit proper planning and strategizing so that maternal morbidity and mortality is reduced. ${ }^{14}$
It is vital for obstetricians and radiologists to be familiar with the risk factors and diagnostic modalities for placenta accreta because of associated risk of life threatening haemorrhage. If there is a strong suggestion of abnormal placental invasion one should consider patient transfer to a tertiary center. Delivery planning may involve an anaesthesiologist, obstetrician, pelvic surgeon such as gynaecologist, intensivist, maternalfoetal medicine specialist, neonatologist, urologist, haematologist, and interventional radiologist to optimise the patient's outcome. ${ }^{15}$ Traditionally the treatment of choice has been hysterectomy due to risk of PPH, which include all the complications like injuries to adjacent pelvic organs, massive blood transfusions, and disseminated intravascular coagulation and high mortality rates. Over the last decade its management has changed from traditional concept of not leaving any part of the placenta in utero to a more conservative approach of leaving the placenta in situ. ${ }^{7,16}$

Post-partum haemorrhage is an important cause of maternal mortality in developing world. Many cases of PPH are associated with retained placenta. Incidence of retained placenta in normal deliveries is 0.6 to $3.3 \%$. $^{6,17,18}$

Intrapartum guidelines produced for the National Institute of Health and Clinical Excellence (NICE) suggest intervention when the placenta has been retained for 30 minutes after the birth, ${ }^{19}$ while World Health Organisation (WHO) recommends waiting for 60 minutes. ${ }^{20}$ In our institution, we define retained placenta after 30 minutes.

There are number of causes that may lead to retained placenta. $^{21}$ Some placentas are trapped behind a closed cervix or a tightened down lower uterine segment known as trapped placenta, some are adherent to the uterine wall but easily separate manually called as placenta adherents, and others are invading the myometrium known as placenta accrete. ${ }^{22}$

In Mullerian anomalies, the mean incidence of bicornuate uterus is $46 \%{ }^{23}$ This anomaly is associated with both fertility and obstetric complication. ${ }^{24}$ In our case placenta was trapped in left cornua of bicornuate uterus.

There are different methods for the management of placenta accreta: ranging from conservative methods to extirpative management. $^{25}$

The conservative methods were first described by Arul Kumaran et al in 1986 in which systemic methotrexate was administered postnatally. It has been hypothesized that methotrexate acts by inducing placental necrosis and expediting a more rapid involution of the placenta. ${ }^{26} \mathrm{As}$ there is no consensus regarding dose, route and frequency of administration of methotrexate, we use two doses of $1 \mathrm{mg} / \mathrm{Kg}$ body weight that is $50 \mathrm{mg}$ intramuscular repeated after one week interval. 
Crespo et al used 4 doses of injection methotrexate 50mgs per day with folinic acid recue. Patient passed fleshy mass 7 months post-delivery. ${ }^{27}$

Sentilhis et al concluded that failure rate of conservative management was $22 \%$ which required hysterectomy, either primary or delayed, mostly for severe haemorrhage. Although conservative treatment is successful in uterine preservation but there are chances of severe maternal morbidity in the form of sepsis including septic shock, peritonitis, uterine necrosis, fistula, injury to the adjacent organs, acute pulmonary oedema, acute renal failure, deep vein thrombophlebitis, pulmonary oedema and death. Most common complication is fever which is due to endometritis or disseminated sepsis. Fever may also be due to tissue necrosis due to inflammatory response in the absence of infection. ${ }^{25}$ Prophylactic broad spectrum antibiotic therapy may reduce incidence of infectious morbidity. ${ }^{28,29,30}$

Our patient also had fever, initially mistaken with fever due to tissue necrosis after methotrexate. But after analysing, investigations concluded this was because of sepsis. Although patient was on broad spectrum inravenous antibiotics.

Timmermans et al reviewed that fever and vaginal bleeding each seen in $35 \%$ of patients on conservative management and lead to hysterectomy in majority of patients. $^{28}$

In our patient, we reported only fever as she was in sepsis so decision of laparotomy taken with informed consent regarding need for hysterectomy. But after intraoperative inspection and consensus decision was to preserve the fertility of patient as she was primiparous. So hysterotomy was done, to remove the placenta and to save her fertility.

There is one case report of hysterotomy for retained placenta in a septate uterus by Daniel Lee and Joseph Johnson. Another case of fertility conserving surgery for retained placenta is by Ashton et al that is hemihysterectomy for placenta accreta in a bicornuate uterus.

\section{CONCLUSION}

This case report describes an unusual case where we managed the retained placenta accreta by avoiding hysterectomy and able to conserve the future fertility in a primiparous patient. However it should be thought in a well-equipped centre where facilities for intensive \& strict monitoring, blood bank and a surgical team with expertise of handling difficult hysterectomy is present round the clock.

Funding: No funding sources Conflict of interest: None declared

Ethical approval: Not required
1. Hughes EC, editor. Obstetric-gynecologic terminology: with section on neonatology and glossary on congenital anomalies. Philadelphia (PA): F.A. Davis; 1972.

2. OyeleseY. SmulianJC. Placentaprevia, placenta accreta and vasa previa. Obstet and Gynecol. 2006;107(4):927-41.

3. Tong SY P, Tay KH, Kwek YCK, Conservative management of placenta accreta: review of three cases. Singapore Medical Journal,2008;49(6):156-9.

4. TimmermansS. VanHofAC. DuvekotJJ. Conservative management of abnormally invasive placentation. Obstetrical and Gynecological Survey. 2007;62(8):529-39.

5. Hudon L, Belfort MA, Broome DR. Diagnosis and management of placenta percreta: a review Obstet Gynecol Survey1998;53:509-17.

6. Gordon JE. Gideo H. Wyon JB. Midwifery practices in rural Punjab, India. American Journal of Obstetrics \& Gynecology.1965;93(5):734-42.

7. Warshak CR. Eskander R. Hull AD. Scioscia AL. Mattrey RF. Benirschke $\mathrm{K}$ et al. Accuracy of ultrasonography and magnetic resonance imaging in the diagnosis of placenta accreta. Obstet Gynecol. 2006;108:573-81.

8. Comstock CH. Love JJ Jr. Bronsteen RA. Lee W. Vettraino IM. Huang RR et al. Sonographic detection of placenta accreta in the second and third trimesters of pregnancy. Am J Obstet Gynecol. 2004;190:113540.

9. Mussalli GM. Shah J, Berck DJ, Elimian A, Tejani N, Manning FA. Placenta accreta and methotrexate therapy: three case reports. J Perinatol. 2000;20:3314.

10. Butt K. Gagnon A. Delisle MF. Failure of methotrexate and internal iliac ballon catheterization to manage placenta percreta. Obstet Gynecol. 2002;99:981-2.

11. Obstetrics: normal and problem pregnancies (4 Ed.). New York, NY [U.A.]: Churchill Livingstone. 2002. P.519.

12. Johnston TA. Paterson-Brown S. (January 2011). Placenta Praevia, Placenta Praevia Accreta and Vasa Praevia: Diagnosis and Management. Green-top Guideline No. 27. Royal College of Obstetricians and Gynecologists.

13. Pliskow. Steven. Dai. Xiaorong. Kohner. Andrew. Kapnick. Jason. Conservative surgical management of placenta accreta, a report of three cases. The journal of reproductive medicine. 2009;54:636-9.

14. Knight M. UKOSS. Peripartum hysterectomy in UK: management and outcomes of the associated haemorrhage. British Journal of Obstetrics and Gynecology. 2007;114:1380-7.

15. Eller AG. Bennett MA. Sharshiner M. Masheter C. Soisson AP. Dodson M et al. Maternal morbidity in cases of placenta accreta managed by a multidisciplinary care team compared with standard obstetric obstetric care. Obstet Gynecol. 2011;117:331-7.

\section{REFERENCES}


16. Comstock $\mathrm{CH}$. Antenatal diagnosis of placenta accreta: a review. Ultrasound Obstet Gynecol. 2005;26:89-96.

17. Combs CA. Laros RK. Prolonged third stage of labour: morbidity and risk factors. Obstet Gynecol. 1991;77:863-7.

18. Tandberg A. Albrechtsen S. Iverson OE. Manual removal of placenta. Acta Obstet Gynecol Scand. 1999;78:33-6.

19. Collaborating Centre for Women and children's Health (NCCWCH) National Intrapartum Care. Care of Healthy Women and their Babies during Child birth, RCOG Press, London, UK, 2007.

20. WorldHealthOrganization (WHO), Pregnancy, Childbirth, Postpartum and new born Care: A Guide for Essential Practice, WHO, Geneva, Switzerland, 2ndedition, 2006.

21. Weeks AD. The retained placenta, Best Practice \& Research: Clinical Obstetrics and Gynaecology. 2008; 22(6):1103-17.

22. Jansen RPS, Elliott PM. Angular intrauterine pregnancy. Obstetrics \& Gynecology. 1981;58(2):167-75.

23. Acien P. Incidence of Mullerian defects in fertile and infertile women. Human Reproduction 1997;12:1372-6.

24. Grimbizis GF, Camus M, Tarlatzis BC, Bontis JN, Devroey P. Clinical implications of uterine malformations and hysteroscopic treatment results. Human Reproduction Update 2001;7:161-74.
25. Sentilhes L, Ambroseli C, Kayem G, Provansal M, Fernandez H, Perrotin F et al. Maternal outcome after conservative treatment of placenta accreta. Obstetrics and Gynaecology. 2010;115:526-34.

26. Arul Kumaran S, Ng CS. Ingemarsson I. Ratnam SS. Medical treatment of placenta accreta with methotrexate. Acta Obstetrics et Gynecologica Scandinavica. 1986;65:285-6.

27. Crespo R, Lapresta M, Madani B. Conservative management of placenta increta with methotrexate. International Journal of Gynecology and Obstetrics. 2005;91:162-3.

28. Timmermans S, Van Hof AC. Duvekot JJ. Conservative management of abnormally invasive placentation. Obstetrical and Gynecological Survey. 2007;62(8):529-39.

29. Kayeg G, Davy C, Goffinet F, Thomas, Clement D, Cabrol D. Conservative versus extirpative management in cases of placenta accreta. Obstetrics and Gynecology. 2004;104(3):531-6.

30. BretelleF, CourbiereB, MazounietalC. Management of placenta accreta: morbidity and outcome. European Journal of Obstetrics Gynecology and ReproductiveBiology.2007;133(1):34-9.

Cite this article as: Sharma R, Gupta A, Chaudhary UK, Sharma A, Kumar A. A rare case report of hysterectomy for retained placenta accreta in bicornuate uterus. Int J Reprod Contracept Obstet Gynecol 2015;4:1622-6. 